МИТРОХИНА Татьяна Николаевна - доктор политических наук, профессор Саратовского социально-экономического института - филиала Российского экономического университета им. Г.В. Плеханова (410003, Россия, г. Саратов, ул. Радищева, 89; mtn002@rambler.ru)

ШАЙДУЛЛОВ Айнур Азатович - аспирант Саратовского социально-экономического института - филиала Российского экономического университета им. Г.В. Плеханова (410003, Россия, г. Саратов, ул. Радищева, 89; mr.ppksgtu@таil.ru)

\title{
ПОЛИТИЧЕСКОЕ ПРОЕКТИРОВАНИЕ: НЕКОТОРЫЕ АСПЕКТЫ ПРОБЛЕМЫ ПРОЕКТИРОВАНИЯ ГРАЖДАНСКОЙ ИДЕНТИЧНОСТИ В СОВРЕМЕННОЙ РОССИИ
}

\begin{abstract}
Аннотация. Авторам близка идея целенаправленного проектирования идентичности с целью получения желаемого результата. Идентичности формируются под влиянием множества разнообразных факторов, в первую очередь естественных, органических или аскриптивных. Однако в контексте проектной проблематики особую значимость приобретает то обстоятельство, что идентичности формируются под влиянием субъективно выстроенных, координируемых, направляемых и управляемых воздействий. Целенаправленное проектирование идентичности может осуществляться субъектами, обладающими легитимным правом на реализацию проекта по управлению сознанием, правом на формирование будущего. Элиты строят и направляют развитие сообщества для обеспечения легитимности, лояльности и порядка. Реализация проекта по формированию идентичности осуществляется по ряду направлений: это определение идеи, способствующей интеграции общества; интерпретация прошлого как основание для формирования будущего; оформление образа желаемого общественного устройства; определение символических границ с «другими».
\end{abstract}

Ключевые слова: политическое проектирование, проектирование идентичности, политический проект, элиты, формирование будущего

И дентичности формируются под влиянием множества разнообразных факторов, в первую очередь естественных, органических или аскриптивных. Однако в контексте проектной проблематики особую значимость приобретает то обстоятельство, что идентичности формируются под влиянием направляемых и координируемых воздействий соответственно содержанию политического проекта. В рамках данной статьи мы руководствуемся авторским определением политического проекта как предлагаемого к производству или уже производимого политического продукта, характеристики которого задаются представлением субъекта проектирования об идеале геополитического будущего, целью, оформленной в рациональных терминах, ожиданием определенного эффекта от реализации проекта, объектами внешнего мира, на которых проект направлен, средствами и условиями, предполагаемым результатом, сроками, алгоритмом и каналами реализации [Митрохина 2015: 73].

Мысль о проектировании и конструировании идентичности достаточно хорошо прочитывается как в научном, так и в политическом дискурсах. Так, например, по убеждению немецкого философа В. Хёсле, одной из главных задач «великого государственного мужа должно быть участие в устроении новой, более разумной идентичности» [Хесле 1994: 121]. По мнению российского философа О. Митрошенкова, формирование идентичности вполне поддается управлению и контролю. Так, например, с его точки зрения, в Украине успешно реализован проект по насильственному разотождествлению, распредмечиванию, проект смены идентичности сотен тысяч людей [Митрошенков 2016: 20]. Глава международной ассоциации неправительственных организаций «Голубой 
щит» К. Габсбург уверен, что главной целью современных международных (межэтнических, межрелигиозных) конфликтов являются не объекты инфраструктуры противника, а национальная идентичность и культурное наследие 1 . Идея целенаправленного проектирования идентичности, ее форматирования и переформатирования с целью получения желаемого результата близка и авторам данной статьи.

В официальном дискурсе российской власти политический проект, направленный на формирование гражданской идентичности, обретает определенные формы в 2011/2012 гг. - в предвыборной программе главного претендента на пост президента страны. Технологической новацией этой избирательной кампании стало общение одного из кандидатов на пост президента страны с гражданами в формате предвыборных статей. В текстах статей прочитываются сюжеты, так или иначе имеющие отношение к проблеме формирования и укрепления идентичности. Выбранный формат коммуникации с обществом в виде статей по наиболее актуальным в масштабе страны проблемам позволил кандидату на пост главы государства инкорпорировать в предвыборную программу размышления о ценностях, справедливости, морали, ответственности, солидарности, смысле жизни - в целом, о философских основаниях российской политики.

В системе ценностно-смысловых координат предвыборной философии проблема идентичности обозначена в качестве наиболее актуальной, без решения которой трудно вести речь о достойном будущем страны. Ее формированию и укреплению отводится существенное место. Признается великая миссия русского народа - объединять, скреплять цивилизацию языком, культурой, «всемирной отзывчивостью». Поставив диагноз настоящему российской политики - «короткое дыхание» и ограниченность вопросами текущего сохранения или передела власти и собственности», - автор статьи переходит к обсуждению собственного видения будущего российского государства, его укрепления и объединения: «да, возможно на короткий период увлечь значительную часть общества звонкими лозунгами, образами прекрасного будущего; но если потом люди не увидят себя в этом будущем - они надолго отвернутся и от политики, и от общественных задач» 2 .

Помимо предвыборных дискуссий, вопросы формирования идентичности заняли достойное место и в послании Федеральному собранию 2012 г. По сути, впервые были озвучены проблемы российского общества, которое испытывает явный дефицит «духовных скреп»: милосердия, сочувствия, сострадания друг другу, поддержки и взаимопомощи. Движение вперед невозможно без сохранения национальной и духовной идентичности. Основу формирования и укрепления гражданской идентичности должны составить ответственность, доверие, прозрачность власти, гражданская солидарность и справедливость - все то, что может способствовать единению граждан ${ }^{3}$.

Вопросы укрепления идентичности составили предмет внимания и далее в рамках международного дискуссионного клуба «Валдай», в работе которого традиционно принимает участие президент страны. В центре дискуссии политиков и экспертов находилась проблема формирования национальной идентичности. «Для россиян, для России вопросы “кто мы?”, “кем мы хотим быть?”

\footnotetext{
1 Рецепт Габсбургов. - Международное обозрение. Эфир от 13.05.2016. Доступ: http://rutv.ru/brand/ show/id/59217 (проверено 14.04.2018).

2 Путин В. Россия сосредотачивается - вызовы, на которые мы должны ответить. 2012. 16 янв. Доступ: http://izvestia.ru/news/511884 (проверено 14.04.2018).

3 Послание Президента РФ Федеральному Собранию РФ. 2012 г. 12 дек. Москва, Кремль. Доступ: http://kremlin.ru/events/president/news/17118 (проверено 03.04.2018).
} 
- звучат все громче и громче. Вопрос обретения и укрепления национальной идентичности действительно носит для России фундаментальный характер»1.

Участники дискуссии пришли к выводу, что под давлением процессов глобализации и распада государства Россия получила разрушительный удар по культурному и духовному коду нации снаружи и изнутри. В современном кардинально меняющемся мире под влиянием глобальных процессов Россия оказалась перед необходимостью поиска новой стратегии и ценностных, культурных, духовных оснований сохранения своей идентичности. Ключевым оказался очевидный и давно назревший вывод о том, что единство и сила государства определяются благополучием граждан. Развитие страны и способность противостоять внешним угрозам определяются духовными, моральными, интеллектуальными качествами людей, единством, традициями, целями, ответственностью и сплоченностью общества.

В рамках форума внимание было уделено поиску идеи, которая может стать основой проекта формирования идентичности. Участники дискуссии согласились с тем, что человек в российском обществе нуждается в гораздо большем внимании со стороны государства, чем это есть в настоящее время. Именно эта идея и была заложена в основание идеологии укрепления идентичности и практической политики. «В сердце нашей философии должно быть развитие человека, развитие моральное, интеллектуальное и физическое». По сути, речь шла о «скрепах», которые необходимы российскому обществу.

Таким образом, различные информационные сюжеты, выступления на форумах, дискуссии сложились в целостную проектную конструкцию по формированию гражданской идентичности российского общества и укреплению его единства.

Цель проекта по формированию идентичности состоит в достижении единства граждан в многонациональном обществе, сохранении индивидуальной идентичности, формируемой на основе уникального опыта конкретного человека, с одновременным конструированием коллективной гражданской идентичности, не сводимой к простой сумме индивидуальных опытов. Гражданская идентичность должна быть сформирована на уровне целого сообщества, члены которого считают «нечто» общим для всех, объединяющим всех независимо от индивидуального опыта. В содержательном отношении проект формирования идентичности противопоставляется и мультикультурному проекту, и проекту «плавильного котла».

Очевидно, идентичность не может быть навязана сверху, не может быть построена на основе идеологической монополии. Однако формирование идентичности сознательно/подсознательно направляется политическими субъектами. Как правило, гражданин оказывается в ситуации, когда фундаментальные принципы внутренней и внешней политики уже определены, и в значительной мере он вынужден принять или не принять выстроенную целенаправленно или оформившуюся под влиянием обстоятельств идентичность.

Гражданская идентичность неразрывно связана с такими понятиями, как общество, государство, страна, Родина, Отечество, самоотождествление с которыми и является основой ее формирования ${ }^{2}$. Поэтому формирование гражданской идентичности рассматривается в качестве необходимого условия интеграции российского общества. На основе общих морально-нравственных ценно-

1 Путин В. Многообразие России для современного мира. Выступление на заседании международного дискуссионного клуба «Валдай». Доступ: http://www.rg.ru/2013/09/19/stenogrammasite.html (проверено 03.04.2018).

2 Гришина Е.А. 2003. Идентичность гражданская. - Социологическая энциклопедия. В 2 т. М.: Мысль. T. 1. C. 336 . 
стей, патриотического сознания, гражданской ответственности и солидарности, уважения к закону, сопричастности к судьбе Родины, но без потери связи со своими этническими, религиозными корнями формирование гражданской идентичности рассматривается в качестве необходимого условия сохранения единства страны ${ }^{1}$.

Этот контекст доминирует в официальном дискурсе власти. Через формирование гражданской идентичности власть способна обеспечить легитимность. Через гражданскую идентичность общество ощущает свою принадлежность к общему делу. Через осознание и принятие общих принципов граждане ощущают причастность к политическому проекту, ориентированному на будущее, определяющему контуры этого будущего, цели, ценности и пути созидания.

Гражданская идентичность выступает не только как теоретический конструкт, но и как практически реализуемый проект политического сообщества. Идентичность, являясь воображаемой сущностью, практически всегда содержит ответ на вопрос: «что мы думаем о самих себе?», «К чему мы стремимся?» [Хантингтон 2004: 51]. Практическая реализация проекта предполагает определение стратегически важных направлений, по которым предстоит работа. Важнейшими направлениями проектирования и конструирования идентичности являются определение идеи, способствующей интеграции общества; формирование представления не только о себе и будущем своего сообщества, но и о других сообществах, в соотнесении с которыми осознаются собственные достоинства, значимость и недостатки. Не менее важны интерпретация прошлого как основание для формирования будущего, оформление образа желаемого общественного устройства, определение символических границ с «другими» [Тимофеев 2008: 19].

Одним из направлений конструирования идентичности является оценка прошлого, отношение к своей истории. Пожалуй, для России не теряет актуальность тезис: «ничто не меняется так быстро, как наше прошлое». В зависимости от ситуации от случая к случаю и по случаю переписываются учебники, замалчиваются или, напротив, раскрашиваются яркими красками отдельные политики или события. При необходимости усиливается роль одного, оставляется незамеченным вклад другого. Современная политика стремится получить дивиденды, ассоциируясь то с достижениями в сфере освоения космического пространства, то с победой в Великой Отечественной войне, то со спортивными победами советских лет. Однако практика доказывает несостоятельность политики, основу которой составляет длительная эксплуатация всего, что создавалось коллективными усилиями советского народа, с одновременной дискредитацией советского наследия. Не удивительно, что вопросы оценки многих исторических событий в современной России остаются «яблоком раздора» и сегодня.

Проект укрепления российской идентичности не может быть реализован вне связи с российской национальной идеей. Основу проекта формирования и укрепления идентичности составляет национальная идея, национальные интересы, ценности, определяющие содержание будущего. Национальная идея в свою очередь является основой определения очертаний будущего государства, в котором хотелось бы жить, которое хотелось бы создать.

Не раз в качестве национальной идеи как основы интеграции общества пред-

\footnotetext{
1 Национальная идентичность и будущее России: доклад международного дискуссионного клуба «Валдай». 2014, февраль. Москва. Доступ: https://www.hse.ru/pubs/share/direct/document/135819049 (проверено 14.04.2018).
} 
лагались патриотизм ${ }^{1}$ и идея социальной справедливости ${ }^{2}$. В результате многочисленных дискуссий и социологических исследований ${ }^{3}$ эксперты пришли к выводу, что сплачивающей и мобилизующей общество идеей, адекватной современной ситуации в мире и стране, может стать идея развития человеческой личности. Стратегия укрепления национальной идентичности как главный приоритет необходима именно в контексте создания среды и воспитания субъектов позитивных изменений - граждан ${ }^{4}$. В целом идея развития человеческого капитала прозвучала убедительно и получила дальнейшее подтверждение в ряде документов. Развитие человеческого капитала в качестве национальной идеи обсуждалось в программе Совета по внешней и оборонной политике «Стратегия XXI»5. В рамках президентского послания Федеральному собранию 2018 г. было заявлено, что приоритет политики страны на предстоящие 6 лет - «сбережение народа России и благополучие наших граждан» 6 .

Чтобы идентифицировать себя, людям нужны «другие». На оформление идентичности оказывает влияние восприятие «других» и восприятие «другими», а в целом - определение границ и содержания оппозиции «мы - они». Советская идентичность формировалась во многом с опорой на конкуренцию со странами капиталистического мира. В свою очередь, идентичность западных стран оформлялась не без помощи стран социалистического блока. Образ внешнего «другого» универсально функционален с точки зрения сплочения общества. Через сравнение и противопоставление с «другими» осознается уникальность собственного политического проекта или его отсутствие. Западные страны после продолжительного периода попыток «сдружиться» сегодня в российском политико-информационном пространстве как никогда ранее актуализированы в качестве «другого» [Тимофеев 2008: 52].

Как и любой другой проект, политический проект, направленный на формирование идентичности, представляет собой интеллектуальную конструкцию, по своей сути устремленную в проектируемое будущее в соответствии с заданными целями, результатами, сроками. Строительство теоретической проектной конструкции, с одной стороны, осуществляется целенаправленно и целерационально субъектами проектирования, с другой - с обязательной опорой на традиции, ценности, значимые для граждан и укорененные в сознании. Без такой опоры проект вряд ли может быть успешным. Отсутствие доверия власти со стороны общества не способствует успешной реализации проекта. Формирование гражданской идентичности подразумевает двусторонний характер отношений: с одной стороны, это понимание обществом своих отношений с государством, с другой - понимание государством своих отношений с обществом [Кравченко 2014: 72].

Дефицит ответственности власти перед обществом, ощущаемый российскими

1 Встреча с активом Клуба лидеров. 03 февраля 2016 г. Доступ: http://kremlin.ru/events/president/ news/51263 (проверено 14.04.2018).

2 Третий медиафорум независимых региональных и местных СМИ «Правда и справедливость». 7 апреля 2016 г. Санкт-Петербург. Доступ: http://kremlin.ru/events/president/news/51685 (проверено 14.04.2018).

3 Доклад ВЦИОМ «Современная российская идентичность: измерения, вызовы, ответы». 2013, сент. Доступ: http://vid-1.rian.ru/ig/valdai/Russian_Identity_2013_rus.pdf (проверено 14.04.2018).

4 Путин В. Многообразие России для современного мира. Выступление на заседании международного дискуссионного клуба «Валдай». Доступ: http://www.rg.ru/2013/09/19/stenogrammasite.html (проверено 14.04.2018).

5 Стратегия - XXI: версия для обсуждения. Доступ: http://svop.ru/проекты/strategy-xxi/9997/ (проверено 14.04.2018).

6 Послание Президента РФ Федеральному Собранию. Москва, Центральный выставочный зал «Манеж». 2018. 1 марта. Доступ: http://kremlin.ru/events/president/news/56957 (проверено 14.04.2018). 
гражданами очень остро, является серьезным препятствием на пути формирования и укрепления идентичности. Укреплению доверия между гражданами и властью не способствует и такое обстоятельство, как существенное снижение уровня жизни большинства российских граждан на фоне сверхобогащения российского истеблишмента. И хотя на уровне деклараций о намерениях по-прежнему есть понимание того, что «без концентрации усилий на формировании взаимной ответственности власти и каждого гражданина и, наконец, на восстановлении доверия в обществе Россия проиграет историческую конкуренцию», реальность оставляет желать лучшего.

Очевидно, такие принципы, как создание условий для развития человеческого потенциала, восстановление доверия граждан и ответственности власти в качестве ценностных оснований политического проекта по формированию и укреплению гражданской идентичности, должны быть не только заявлены декларативно, но и реализованы на практике.

Данный вид проектирования осуществляется в области тонких материй. Однако, будучи связанным с индивидуальным и коллективным сознанием, являясь, по сути, рациональным видом деятельности, он вторгается в область иррационального. В основание теоретической конструкции заложены духовные представления, на основе которых далее формируются вполне материальные политические институты и практики.

Как и в любом другом проекте, ключевым элементом здесь является идея, на которую опирается представление о будущем государства и общественного устройства. Чтобы сплотить граждан в единое сообщество и стать основой формирования идентичности, идея должна быть предметом и результатом общественного согласия. В пределах общественного договора необходимо достигнуть консенсуса относительно общих для всех, а не для отдельных элитных групп принципов и убеждений. Наиболее важными составляющими общественного обсуждения и согласия являются такие составляющие общественного согласия в современной России, как принципы справедливости, солидарности, ответственности и доверия. Предметом общественного согласия должны стать содержание и принципы политического проекта, направленного на формирование единого сообщества, в пределах которого участники соглашения должны разделять общие ценности, принципы и убеждения.

\section{Список литературы}

Кравченко С.А. 2014. Влияние «нормальной аномии» на общероссийскую гражданственность: возможности минимизации ее эффектов. - Позитивный опыт регулирования этносоциальных и этнокультурных процессов в регионах Российской Федерации: материалы всероссийской научно-практической конференции. Казань, 25-27 сентября 2014 г. Институт истории им. Ш. Марджани AH PT.

Митрохина Т.Н. 2015. Объяснительные возможности концепта «политический проект» (на материалах сайта Института динамического консерватизма). - Вестник Московского университета. Сер. 12. Политические науки. № 4. C. 71-90.

Митрошенков О.А. 2016. Идентичность: от теоретического концепта к управленческим воздействиям. - Власть. № 2. С. 14-28.

Тимофеев И.Н. 2008. Политическая идентичность России в постсоветский период: альтернативы и тенденции. М.: Изд-во МГИМО(У). 176 с.

Хантингтон С. 2004. Кто мы?: Вызовы американской национальной идентичности. М.: АСТ; Транзиткнига. 635 с. 
Хесле В. 1994. Кризис индивидуальной и коллективной идентичности. Вопросы философии. № 10. С. 112-123.

MITROKHINA Tatyana Nikolaevna, Dr.Sci. (Pol.Sci.), Professor of the Chair of History, Philosophy and Political Science, Saratov Socio-Economic Institute - the branch of Plekhanov Russian University of Economics (89 Radischeva St, Saratov, Russia, 410003; mtn002@rambler.ru)

SHAYDULLOV Ainur Azatovich, postgraduate student of Saratov Socio-Economic Institute - the branch of Plekhanov Russian University of Economics (89 Radischeva St, Saratov, Russia, 410003; mr.ppksgtu@mail.ru)

\title{
POLITICAL DESIGN: SOME ASPECTS OF THE PROBLEM OF DESIGNING CIVIL IDENTITY IN MODERN RUSSIA
}

\begin{abstract}
Within the framework of the article, an analysis of the formation of civil identity in modern Russian society in the context of project problems is proposed. The authors maintain the idea of purposeful design, formatting of identity in order to obtain the desired result. Identities are formed under the influence of a variety of different factors, primarily natural, organic or ascriptive. However, in the context of the project problematic, the fact that identities are formed under the influence of subjectively built, coordinated, directed and controlled impacts acquires special significance.

A targeted design of identity can be carried out by entities that have a legitimate right to implement a project to manage consciousness, and to form a future. Elites build and direct the development of the community to ensure legitimacy, loyalty and order. The realization of the project on the formation of identity is carried out in a number of directions, such as the definition of an idea that fosters the integration of society; the interpretation of the past as the basis for shaping the future; the design of the desired public device; the definition of symbolic boundaries with others.

Keywords: political project, design of identity, elites, shaping of future
\end{abstract}

АЛИХАНОВА Сайкинат Арсланалиевна - кандидат политических наук, доцент кафедры социогуманитарных дисииплин Дагестанского государственного педагогического университета (367000, Россия, Республика Дагестан, г. Махачкала, ул. Нахимова, 5a-57; sakinat-alikhanova@yandex.ru)

\section{ОСОБЕННОСТИ МОЛОДЕЖНОГО ПАРЛАМЕНТАРИЗМА В РЕСПУБЛИКЕ ДАГЕСТАН}

Аннотация. В статье рассматривается специфика молодежного парламентаризма в Дагестане как одной из форм политического участия молодежи. Подчеркивается важность и актуальность молодежной политики и молодежного политического участия в республике, где треть населения составляют молодые граждане до 35 лет. Исследуются особенности деятельности и политическая роль молодежного парламента при Народном собрании Республики Дагестан. Автор выделяет основные проблемы, препятствующие развитию политического участия дагестанской молодежи, ключевыми среди которых являются аполитичность и низкая политическая грамотность большинства молодых граждан республики.

Ключевые слова: молодежные организации, молодежный парламент, политические партии, политическое участие, молодежная политика

$\mathrm{M}$ олодежь как наиболее активная часть населения формирует образ будущего, поэтому проблема политического участия молодежи является все более актуальной в практической политике. Тем не менее политологи сходятся во мнении, что в современной России механизмы участия молодежи в госу- 